\title{
Histomorphological Analysis of Upper Gastrointestinal Endoscopic Biopsies: A Retrospective Study of 106 Cases
}

\author{
BHARGAVI MOHAN ${ }^{1}$, HK MANJUNATH ${ }^{2}$, V GEETHAMANI ${ }^{3}$, VC DHARANI ${ }^{4}$, TA SUSHMA ${ }^{5}$, B AKSHATHA ${ }^{6}$
}

\section{ABSTRACT}

Introduction: A variety of disorders affect the upper gastrointestinal tract. Study of endoscopic biopsies is imperative to make an accurate diagnosis, which will aid in early diagnosis and appropriate management of the patient.

Aim: To determine the histomorphological spectrum and the occurrence of upper gastrointestinal lesions; and also to associate endoscopic diagnosis with histopathology.

Materials and Methods: This was a retrospective, descriptive study conducted from May 2017 to April 2019 on 106 cases, done at BGS Global Institute of Medical Sciences, Bengaluru, Karnataka, India. Microscopic findings were studied by two pathologists.

Results: A total of 106 cases were studied. Majority of the patients $(56 \%)$ presented with abdominal pain followed by dyspepsia and dysphagia. Stomach was the most common site of biopsy followed by oesophagus and duodenum. Majority of oesophageal and gastric biopsies were found to be neoplastic i.e., $70.8 \%$ and $56.3 \%$ respectively; however, non-neoplastic lesions formed the majority in duodenal biopsies (88.9\%). The most common malignancy was squamous cell carcinoma, which occurred predominantly in the middle third of the oesophagus. The most common malignancy in the stomach was adenocarcinoma. Correlation between endoscopic diagnosis and histopathology was done in 70 cases; and there was consensus in $78.5 \%$ of the cases (55/70 cases).

Conclusion: Endoscopy with assisted biopsy is the gold standard for diagnosis of upper gastrointestinal disorders. An interdisciplinary approach towards diagnosis and treatment involving the pathologist and clinician is important.

Keywords: Endoscopy, Histopathology, Upper gastrointestinal tract

\section{INTRODUCTION}

Endoscopy with biopsy is important for the diagnosis and treatment of various diseases of the upper gastrointestinal tract. Implementation of recent protocols for taking biopsies and usage of appropriate classifications for reporting biopsies has revolutionised our understanding of the basic pathology [1]. However, due to the differences between recommendations and clinical practice, it is imperative to address the challenges of endoscopic biopsies [2]. The aim of this study was to determine the occurrence as well as the histomorphological spectrum of upper gastrointestinal lesions and to correlate endoscopic diagnosis with histopathology.

\section{MATERIALS AND METHODS}

This was a retrospective, descriptive study conducted from May 2017 to April 2019. The study was conducted among 106 cases who underwent upper gastrointestinal endoscopy at our tertiary care centre in Bengaluru, Karnataka, India.

Inclusion criteria: All endoscopic biopsies of the upper gastrointestinal tract.

Exclusion criteria: 1. Lesions of the oral cavity and pharynx. 2. Lesions below the second part of duodenum.

The biopsies were fixed in 10\% formalin and routinely processed and embedded in paraffin with mucosal surfaces uppermost. Five micron thick sections were cut perpendicular to this surface. Routine staining with hematoxylin and eosin along with special stains like Periodic Acid Schiff, Giemsa and Alcian blue, wherever needed, were performed. Microscopic findings were studied by two pathologists independently. Tumors were diagnosed according to the recent $\mathrm{WHO}$ classification (2010) [3].

\section{STATISTICAL ANALYSIS}

The collected data were entered and analysed using Microsoft excel. The data were expressed in percentages (\%).

\section{RESULTS}

A total of 106 cases were studied. Stomach (60\%) was the most common site of biopsy followed by Oesophagus (23\%) and Duodenum (17\%). [Table/Fig-1] shows the distribution of neoplastic and non-neoplastic lesions in oesophagus, stomach and duodenum. Majority of the patients (56\%) presented with abdominal pain [Table/ Fig-2] followed by dyspepsia and dysphagia.

\begin{tabular}{|l|c|c|c|}
\hline Site of biopsy & Non-neoplastic $\mathrm{n}(\%)$ & Neoplastic $\mathrm{n}(\%)$ & Total $\mathrm{n}(\%)$ \\
\hline Oesophagus & $07(29.2 \%)$ & $17(70.8 \%)$ & $24(22.6 \%)$ \\
\hline Stomach & $28(43.7 \%)$ & $36(56.3 \%)$ & $64(60.4 \%)$ \\
\hline Duodenum & $16(88.9 \%)$ & $02(11.1 \%)$ & $18(17 \%)$ \\
\hline Total & $51(48.1 \%)$ & $55(51.8 \%)$ & $106(100 \%)$ \\
\hline
\end{tabular}

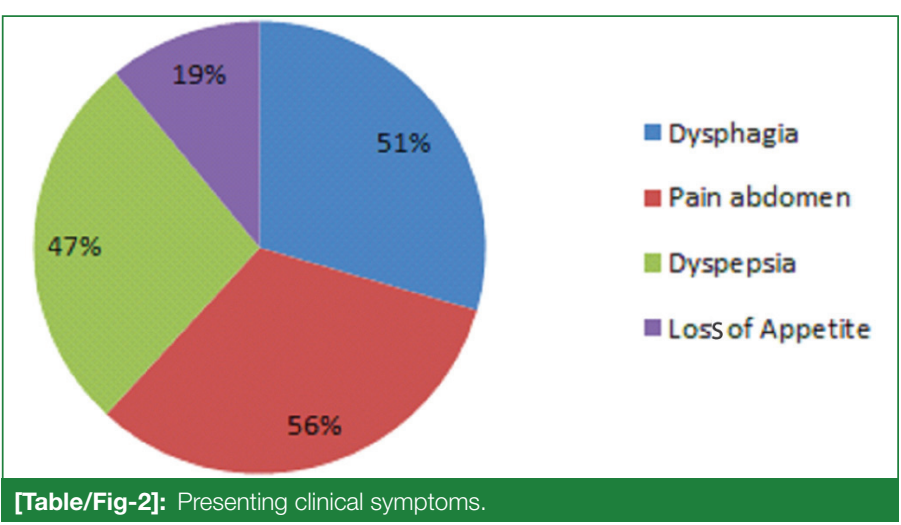


A total of 24 cases of oesophageal biopsies were studied of which 17 were neoplastic and 07 were non-neoplastic. The most common malignancy was Squamous cell carcinoma, which occurred most commonly in the middle third of the oesophagus [Table/Fig-3].

\begin{tabular}{|c|c|c|c|c|c|c|}
\hline \multirow[b]{2}{*}{ Site } & \multicolumn{2}{|c|}{ Barrett's oesophagus } & \multirow{2}{*}{$\begin{array}{c}\text { Squamous } \\
\text { cell } \\
\text { carcinoma }\end{array}$} & \multirow{2}{*}{$\begin{array}{l}\text { Adeno- } \\
\text { squamous } \\
\text { carcinoma }\end{array}$} & \multirow[b]{2}{*}{$\begin{array}{c}\text { Adeno } \\
\text { carcinoma }\end{array}$} & \multirow[b]{2}{*}{ Total } \\
\hline & $\begin{array}{c}\text { low } \\
\text { grade } \\
\text { dysplasia }\end{array}$ & $\begin{array}{c}\text { High } \\
\text { grade } \\
\text { dysplasia }\end{array}$ & & & & \\
\hline Upper third & - & - & 01 & - & - & 01 \\
\hline Middle third & - & 01 & 08 & - & - & 09 \\
\hline Lower third & 01 & 02 & 02 & 01 & 01 & 07 \\
\hline Total & 01 & 03 & 11 & 01 & 01 & 17 \\
\hline
\end{tabular}

[Table/Fig-3]: Distribution of oesophageal carcinomas based on site $(n=17)$

Sixty four cases of gastric biopsies were studied of which 36 were neoplastic and 28 were non-neoplastic. The majority (42.9\%) of non-neoplastic lesions in gastric biopsies were of Chronic Gastritis with H.pylori infestation [Table/Fig-4,5].
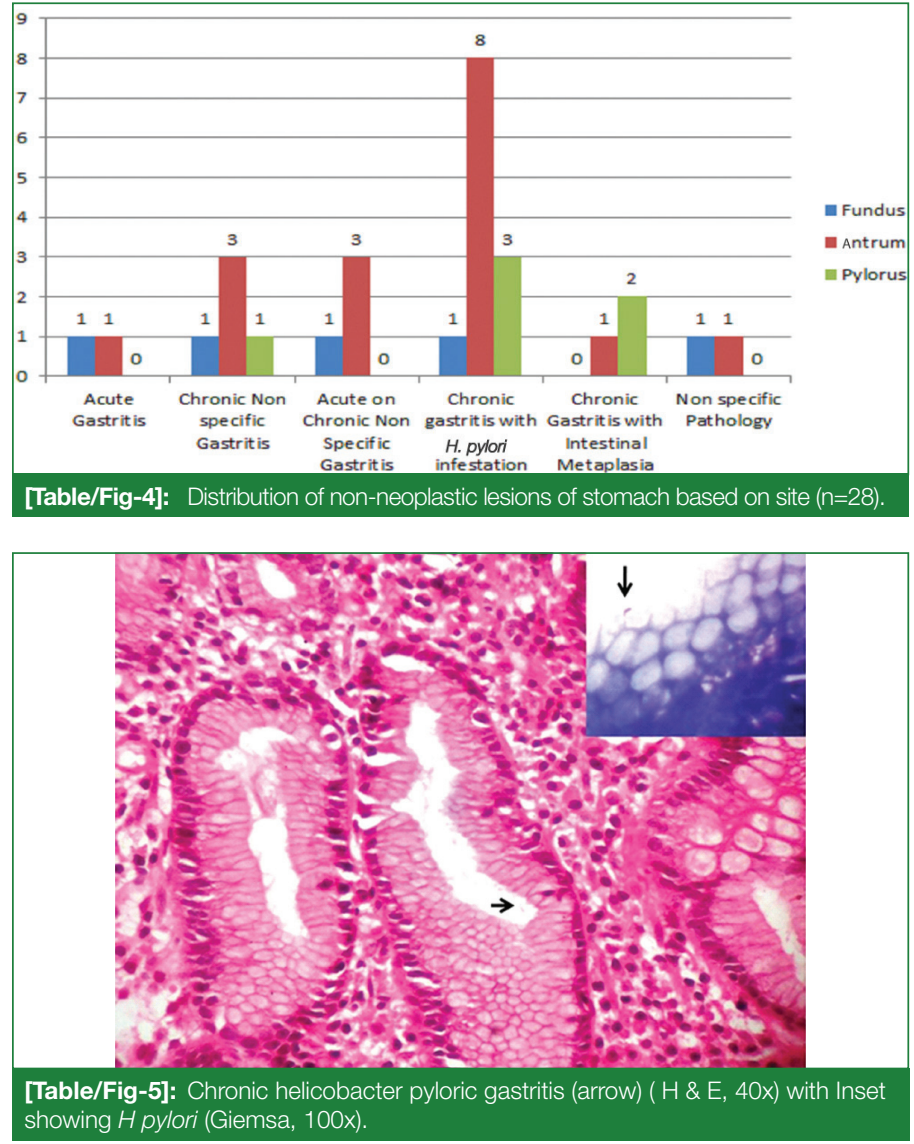

Of the 36 neoplastic lesions of the stomach, 21 cases $(58.3 \%)$ presented as ulceroproliferative lesions endoscopically, followed by ulcerative lesions, seen in 11 cases (30.6\%) [Table/Fig-6]. The most common malignancy was Adenocarcinoma reported in 34 cases (94.4\%) and it was predominantly seen in the antrum (73.5\%) [Table/Fig-7,8].

\begin{tabular}{|l|c|c|c|c|}
\hline Endoscopic finding & Adenocarcinoma & Lymphoma & $\begin{array}{c}\text { Gastrointestinal } \\
\text { stromal tumor }\end{array}$ & Total \\
\hline Ulcerative/ erosive & 10 & 01 & & 11 \\
\hline Ulceroproliferative & 20 & & 01 & 21 \\
\hline Flattening of mucosa & 02 & & & 02 \\
\hline Erythema & 02 & & & 02 \\
\hline Total & 34 & 01 & 01 & 36 \\
\hline
\end{tabular}

[Table/Fig-6]: Endoscopic findings of gastric malignancy along with its histological diagnosis $(\mathrm{n}=36)$.

Eighteen cases of duodenal biopsy were studied of which 16 were non-neoplastic and 02 were neoplastic [Table/Fig-9]. We had one case of duodenal carcinoid [Table/Fig-10] and one case of adenocarcinoma.
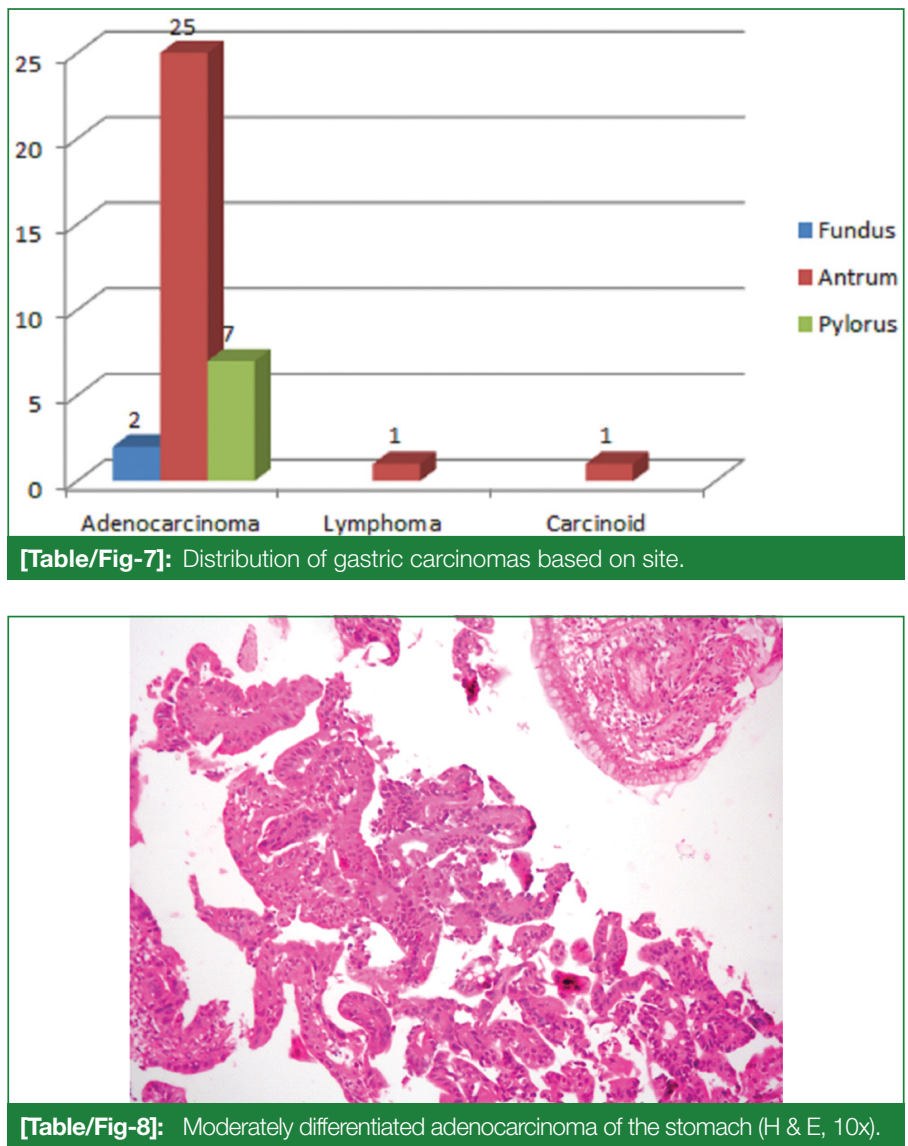

\begin{tabular}{|l|c|}
\hline Disorder & Number of cases \\
\hline Non-specific duodenitis & 13 \\
\hline Celiac sprue & 03 \\
\hline Duodenal carcinoid & 01 \\
\hline Adenocarcinoma & 01 \\
\hline [Table/Fig-9]: Distribution of duodenal lesions $(\mathrm{n}=18)$. \\
\hline
\end{tabular}

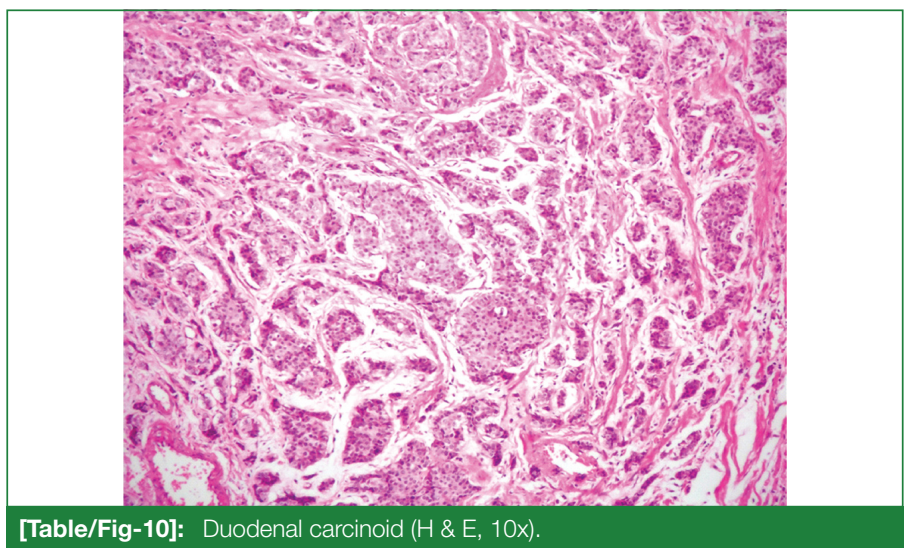

Of the 106 cases studied; in 70 cases, there was association done between endoscopic diagnosis and histopathology; and there was consensus in $78.5 \%$ of the cases. Correlation of endoscopic diagnosis with histopathology was done in 20 oesophageal cases. Endoscopic diagnosis correlated with 15 out of 17 neoplastic lesions (88.2\%) and 2 out of 3 non-neoplastic lesions (66.6\%). Of the 64 stomach biopsies, endoscopic correlation was done in 50 cases. Endoscopic diagnosis correlated with 28 out of 36 neoplastic lesions (78\%) and 10 out of 14 non-neoplastic lesions (70\%).

\section{DISCUSSION}

An important principle of gastrointestinal biopsy interpretation is that the gastrointestinal tract has a limited set of responses to numerous 
injuries. Therefore, accurate, clinical and endoscopic information affects the quality of the report. A systematic approach is warranted while reporting because it can occasionally be life-saving, but more often can be reassuring to most patients undergoing gastrointestinal biopsies [1].

Few important points are to be borne in mind while taking a biopsy from oesophagus. In cases of gastroesophageal reflux disease, a biopsy is recommended only when there is visible mucosal irregularity. Presence of inflammatory signs without any mucosal change doesn't warrant a biopsy. In infectious oesophagitis, such as CMV oesophagitis, biopsies should be taken from the base of the ulcer. For herpes infection, biopsies from the edge of the ulcer are contributory. Protocol of Seattle, includes 4 quadrant biopsies with each biopsy measuring 1-2 cm long are taken; for suspicious Barrett's oesophagus and malignancies [2]. Of the 24 oesophageal biopsies studied, 07 were non-neoplastic and 17 were neoplastic. Majority of the non-neoplastic lesions were chronic non-specific oesophagitis similar to findings observed by Krishnappa $R$ et al., [4]. Oesophageal carcinoma was commonly seen in the middle third, in the present study, similar to studies done by Krishnappa R et al., Rao DN et al., Rumana M et al., [4-6].

Helicobacter pylori has been implicated in many cases of peptic ulcer diseases. The endoscopy based tests for $\mathrm{H}$. pylori include urease test, histological and immunohistochemical evaluation and culture tests $[7,8]$. It is recommended that one or two biopsies be taken $5 \mathrm{~cm}$ proximal to the pylorus, in the lesser curvature near the incisura angularis or in the great curvature opposite to the incisura angularis [9]. Proton Pump Inhibitors should be stopped at least one week before the endoscopy. Recent literatures have described two biopsy protocols; the three biopsy approach and the protocol of Sydney, both with similar sensitivity $[7,10]$. In routine clinical practice, Gastroenterologists don't adhere to such a rigorous sampling and labelling protocol [11]. The Sydney system guidelines can be applied only when a full set of biopsy specimen is available. No attempt is to be made without a complete set; instead an empirical approach is recommended [10]. Chronic $H$. pylori gastritis was seen in $42.8 \%$ of the non-neoplastic gastric biopsies followed by chronic non-specific gastritis (17.8\%); similar to studies done by Memon F et al., [12]. Helicobacter pylori were positive in 12 patients. All cases were confirmed with giemsa stain. $H$. pylori are slender, curved spirals but following treatment with proton pump inhibitors, $H$. pylori may present in the stomach as coccoid forms [13]. Coccoid forms are difficult to recognise at histology, do not produce urease, and are not culturable in vitro [14]. With only focal residual and scanty bacteria, immuno-histochemistry with anti $H$. pylori antibody staining provides a reliable semi-quantitative diagnosis of $H$. pylori infection $[14,15]$. Detection of coccoid forms may be important because they have been reported to be associated significantly more often with gastric adenocarcinoma than with benign peptic ulcers [16].

$H$. pylori induced gastritis has now been implicated in increasing the risk for developing gastric carcinoma by five to six folds $[17,18]$. The biopsies in the stomach should be directed to the presence of ulcers, nodules, polyps, or masses for the exclusion of malignancy [2]. Our study is in concordance with other studies where adenocarcinomas accounted for $90-95 \%$ of gastric cancers $[17,18]$. However, the higher incidence of adenocarcinomas in our study could be attributed to missing out the sub-mucosal lesions which are not easily accessible to biopsy, similar to observations made by Prasad S et al., [19]. Adenocarcinoma in the stomach was seen in $94.4 \%$ of the neoplastic gastric biopsies followed by one case each of Lymphoma and Gastrointestinal stromal tumour [Table/Fig-11]. Presence of fungal infections in cancers, could be attributed to a failure of the immune defense mechanisms in association with cancers [19]. Fungal infection [Table/Fig-12] was noted in two cases of adenocarcinoma. Our study had 2 signet ring cell carcinomas. In one case, we received an ovarian mass which showed signet ring cells in the ovarian stroma and was therefore diagnosed as krukenberg tumour. This case on further examination and endoscopic biopsy from antrum of stomach revealed signet ring cell carcinoma. Signet ring cells may be present in single and in small nests. Special stains (Periodic acid schiff stain) helped to detect the sparsely dispersed tumour cells in the stroma [Table/Fig-13].
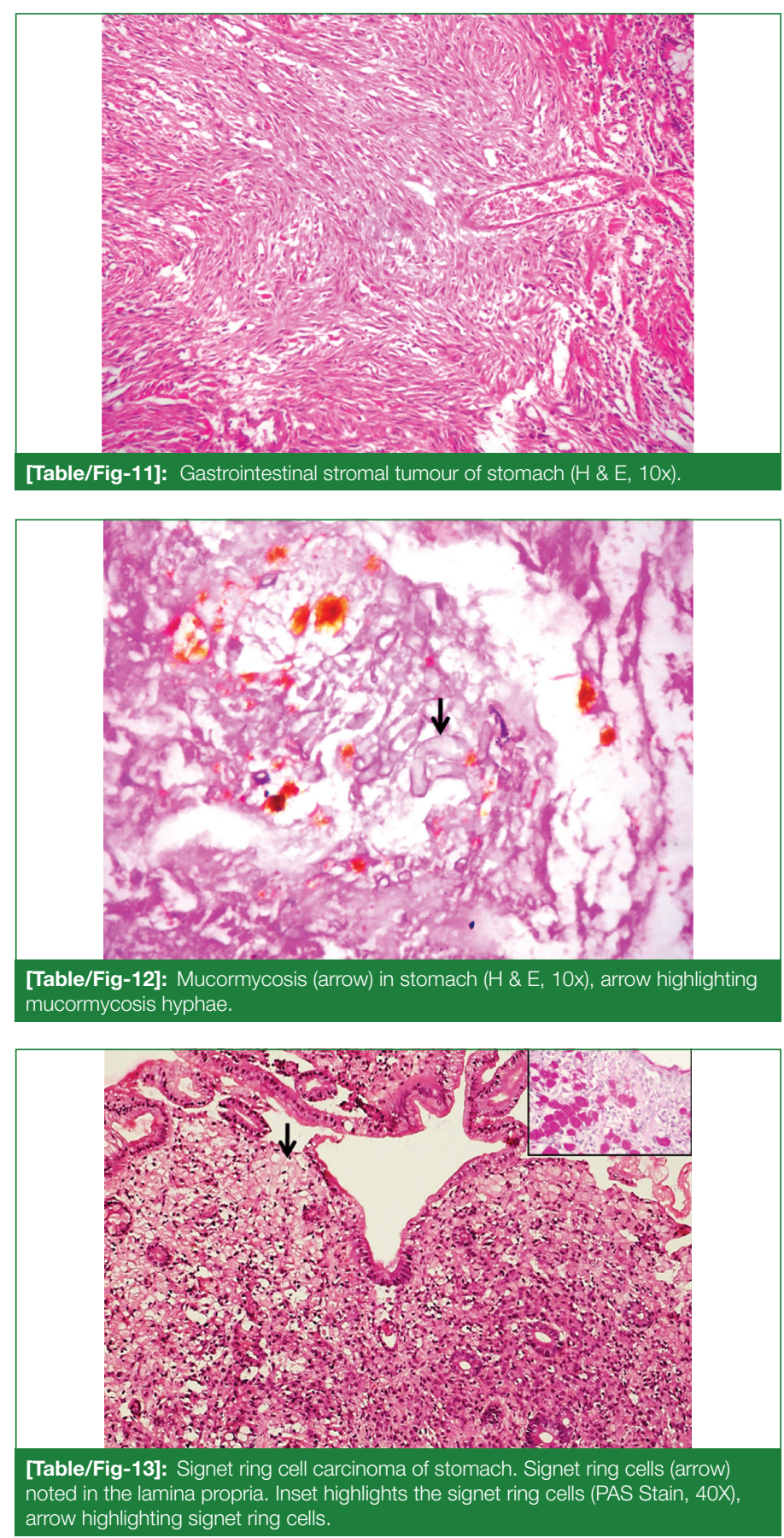

Duodenum has a rich rapidly regenerating epithelial lining which can easily be affected by any inflammatory insult like that seen in celiac disease [20]. For malabsorption conditions such as celiac disease, four to six biopsies from the duodenal bulb and distal duodenum is recommended. Biopsies for minor abnormalities of the duodenal mucosa should be avoided since they don't yield much on histopathology. In cases suspicious of malignancy, multiple biopsies ( $\geq 8$ ) from the base and edges are recommended [2].

Among the duodenal biopsies received, the most common case reported was chronic non-specific duodenitis (72\%), similar to observations made by Krishnappa $R$ et al., [4], followed by 3 cases of celiac sprue, one case of carcinoid and one case of adenocarcinoma.

Of the 106 cases studied; in 70 cases, there was a correlation done between endoscopic diagnosis and histopathology; and there was 
consensus in $78.5 \%$ of the cases. Endoscopic correlation was more in oesophageal neoplasms (88.2\%) as compared to neoplasms of stomach (78\%) similar to observations made by Krishnappa $\mathrm{R}$ et al., and Kazi Jl et al., [4,21]. This may be attributed to the fact that oesophageal carcinomas presents at a later stage, and hence are picked more easily by endoscopy. Also, malignancies of stomach commonly present with ulcers or flat lesions which may be missed on endoscopy. Therefore, endoscopic examination followed by histopathology will yield a more accurate diagnosis. The individual accuracy and sensitivity of these techniques is subjective to the operator's ability and expertise. Furthermore, it is important to look at common diseases that affect people in our part of the world in order to understand various aetiological factors involved in the pathogenesis of these disorders [12].

\section{LIMITATION AND FUTURE RECOMMENDATIONS}

However, due to the limited sample size in our study, further studies needs to be done to establish the significance of correlation between the endoscopic and histopathological diagnosis.

\section{CONCLUSION}

In this study, there was a good correlation observed between endoscopic and histopathological diagnosis. In cases where there was a disagreement in the diagnosis, histopathology proved to be a useful and important tool in making an accurate diagnosis. Histopathologic examination in combination with clinical history, endoscopic findings and special stains, serves as the gold standard for arriving at a diagnosis. Protocol based tissue sampling along with usage of appropriate reporting systems will help in providing an accurate diagnosis.

\section{ACKNOWLEDGEMENT}

We acknowledge surgery department, BGS GIMS for providing us the cases

\section{REFERENCES}

[1] Montgomery E, Voltaggio L. Biopsy interpretation of the gastrointestinal tract mucosa volume 1: Non-Neoplastic. $2^{\text {nd }}$ ed. Lippincott Williams and Wilkins, Philadelphia: 2012
[2] Peixoto A, Silva M, Pereira P, Macedo G. Biopsies in gastrointestinal endoscopy: When and how. GE Port J Gastroenterol. 2016;23(1):19-27.

[3] Bosman F, Carneiro F, Hruban R, Theise N (Eds.) WHO Classification of Tumours of the Digestive System. $4^{\text {th }}$ ed. WHO Press, Lyon: 2012.

[4] Krishnappa R, Horakerappa M. Ali K, Gouri M. A study on histopathologica spectrum of upper gastrointestinal tract endoscopic biopsies. Int J Med Res Health Sci. 2013;2(3):418-24.

[5] Rao DN, Desai PB, Ganesh B. Epidemiological observation of cancer of the esophagus-A review of Indian studies. Indian J Cancer. 1996;33:55-75.

[6] Rumana M, Khan AR, Khurshid N. The changing pattern of oesophago-gastric cancer in Kashmir. JK-Practitioner. 2005;12(4):189-92.

[7] Sharaf RN, Shergill AK, Odze RD, Krinsky ML, Fukami N, Jain R, et al. Endoscopic mucosal tissue sampling. Gastrointest Endosc. 2013;78:216-24.

[8] Loughrey MB, Johnston BT. Guidance on the effective use of upper gastrointestinal histopathology. Frontline Gastroenterology. 2014;5(2):88-95.

[9] Midolo P, Marshall BJ. Accurate diagnosis of Helicobacter pylori. Gastroenterology Clinics of North America. 2000;29(4):871-78.

[10] El-Zimaity HM, Graham DY. Evaluation of gastric mucosal biopsy site and number for identification of Helicobacter pylori or intestinal metaplasia: Role of the sydney system. Human Pathology. 1999;30(1):72-77.

[11] Lash RH, Lauwers GY, Odze RD, Genta RM. Inflammatory Disorders of the Stomach. In Odze RD, Goldblum JR (Eds.) Surgical Pathology of the Gl Tract, Liver, Biliary Tract, and Pancreas. $3^{\text {rd }}$ ed, Saunders, Philadelphia; 2015;269-320.

[12] Memon F, Baloch K, Memon AA. Upper gastrointestinal endoscopic biopsy; morphological spectrum of lesions. Professional Med J. 2015;22(12):1574-79.

[13] Owen D. The Stomach. In: Mills S, Carter D, Greenson J, Oberman H, Reuter V, Stoler M (Eds.) Sternberg's Diagnostic Surgical Pathology. $4^{\text {th }}$ ed, Lippincott Williams and Wilkins, Philadelphia: 2004;1284-86.

[14] Maher TM, Marconi S, Garb J, Otis C, Nash S. Endoscopic biopsy pathology of helicobacter pylori gastritis. Comparison of bacterial detection by immunohistochemistry and genta stain. Arch Pathol Lab Med. 1999;123:778-81.

[15] Tokunaga Y, Shirahase H, Yamamoto E, Gouda Y, Kanaji K, Ohsumi K Semiquantitative evaluation for diagnosis of Helicobacter pylori infection in relation to histological changes. Am J Gastroenterol. 1998;93:26-29.

[16] Chan WY, Hui PK, Leung KM, Chow J, Kwok F, Ng CS. Coccoid forms of Helicobacter pylori in the human stomach. Am J Clin Pathol. 1994;102:503-07.

[17] Duduyemi B, Ojo B, Olaomi O, Atiba A. Histopathological pattern of endoscopic gastric biopsy in a district hospital in Nigeria: A review of 118 consecutive cases. American Journal of Medical and Biological Research. 2014;2(3):83-86.

[18] Normark S, Nilsson C, Normark BH, Hornef MW. Persistent infection with Helicobacter pylori and the development of gastric cancer. Adv Cancer Res. 2003;90:63-69.

[19] Prasad S, Ravindra S, Venkat G, Venugopal S. Gastric neoplasms: An endoscopic biopsy study with review of literature. International Journal of Biomedical Research. 2013;4(12):704-12.

[20] Oberhuber G, Granditsch G, Vogelsang H. The histopathology of coeliac disease. Eur J Gastroenterol Hepatol. 1999;11(10):1185-94.

[21] Kazi JI, Alam SM, Kazi AM, Anwar A, Shamsi Z. Correlation of endoscopic and histologic diagnosis in upper gastrointestinal lesions. J Pak Med Assoc. 1990;40(12):281-83.

\footnotetext{
PARTICULARS OF CONTRIBUTORS:

1. Associate Professor, Department of Pathology, BGS Global Institute of Medical Sciences, Bengaluru, Karnataka, India.

2. Professor, Department of Pathology, BGS Global Institute of Medical Sciences, Bengaluru, Karnataka, India.

3. Professor, Department of Pathology, BGS Global Institute of Medical Sciences, Bengaluru, Karnataka, India.

4. Assistant Professor, Department of Pathology, BGS Global Institute of Medical Sciences, Bengaluru, Karnataka, India.

5. Associate Professor, Department of Pathology, BGS Global Institute of Medical Sciences, Bengaluru, Karnataka, India.

6. Assistant Professor, Department of Pathology, BGS Global Institute of Medical Sciences, Bengaluru, Karnataka, India.
}

NAME, ADDRESS, E-MAIL ID OF THE CORRESPONDING AUTHOR:

Dr. HK Manjunath,

\#2396, $8^{\text {th }}$ Main, $22^{\text {nd }}$ Cross, Banashankari $2^{\text {nd }}$ Stage, Bengaluru-560060, Karnataka, India

E-mail: hk_manjunath70@yahoo.in

Date of Submission: Jun 13, 2019

Date of Peer Review: Jun 24, 2019

Date of Acceptance: Jul 27, 2019

Date of Publishing: Oct 01, 2019 